\title{
Measurement and Frequency Weighting Functions for Human Vibration
}

\author{
Dohyung Kee ${ }^{1}$, Hee Sok Park ${ }^{2}$ \\ ${ }^{1}$ Department of Industrial and Management Engineering, Keimyung University, Taegu 704-701 \\ ${ }^{2}$ Department of Industrial Engineering, Hongik University, Seoul 121-791
}

\begin{abstract}
Objective: The aim of this study is to review and summarize human vibration measurement process, and necessity and methods of frequency weightings for human vibration. Background: Prolonged human exposure to hand-arm vibration and whole-body vibration can result in a range of adverse conditions and the development of occupational diseases such as vibration white finger. For preventing these adverse effects, it is important to correctly apply human vibration measurement process. Method: This manuscript was based on the review and summary of mechanical and human vibration relevant texts, academic papers, materials obtained through web surfing. Results: This manuscript summarizes human vibration measurement process described in ISO standards and relevant texts. The sensitivity of the human body to mechanical vibration is known to be dependent on both the frequency and direction of vibration. To take this into account, varying frequency weighting functions have been developed, and RMS frequency-weighted accelerations are used as the most important quantity to evaluate the effects of vibration on health. ISO provided nine frequency weighting functions in the form of curves and tables. Researches on frequency weightings are focused on development and validation of new frequency weightings to truly reflect the relationship between vibration exposure and its adverse effects. Application: This would be useful information for systematically applying human vibration measurement and analysis process, and for selecting appropriate frequency weighting functions.
\end{abstract}

Keywords: Vibration, Human vibration, Frequency weighting

\section{Introduction}

진동은 물체의 위치, 전류의 세기 등 물리량이 일정 시간 마다 일정한 값으로 규칙적으로 변동하는 현상으로 정의된 다. 질량과 탄성을 갖는 모든 물체는 진동할 수 있으며, 진동 은 크게 자유진동, 강제진동, 자려(自励)진동의 3 종류로 대 별할 수 있다(KSNVE, 1995; Naver, 2013). 인체진동은 기 계적 진동이 인체에 미치는 영향으로 정의되며, 의자나 바닥
과 발을 통하여 전달되는 전신진동과 손-팔 진동으로 구분 할 수 있다(Goglia et al., 2003). 증기롤러 (steamroller), 덤 프트럭, 토목 장비와 같은 중량자동차(heavy-duty vehicle), 버스, 승용차, 건물, 수공구 등의 사용으로 인한 진동에 장기 간 노출될 경우, 요통, 치질, 탈장, 백지병 (vibration white finger: VWF)과 같은 질환과 불편, 멀미, 인지력 및 작업 수행도 저하와 같은 문제를 초래할 수 있다(Kumar, 2004, McCalling et al., 2010). 우리나라에서는 2010년 발병한 직 업병 6,986 건 중 15 건 $(0.21 \%)$ 이 진동장해 질환으로 그 발

Corresponding Author: Dohyung Kee. Department of Industrial and Management Engineering, Keimyung University, Taegu, $704-701$.

Mobile: +82-10-5656-1260, E-mail: dhkee@kmu.ac.kr

Copyright@2013 by Ergonomics Society of Korea(pISSN:1229-1684 eISSN:2093-8462). All right reserved.

(c) This is an open-access article distributed under the terms of the Creative Commons Attribution Non-Commercial License(http://creativecommons.org/licenses/by-nc/3.0/), which permits unrestricted non-commercial use, distribution, and reproduction in any medium, provided the original work is properly cited. http://www.esk.or.kr 
병이 많지 않으나, 영국에서는 가장 많은 직업병 중의 하나 인 것으로 알려져 있다(Ministry of Employment and Labor, 2011; Norsonic, 2013). 이러한 진동으로 인한 부작용을 예 방하기 위하여 ISO (International Standard Organization), European Council 등에서는 진동의 최대 노출 수준을 정하 고 있으며, 우리나라에도 소음진동규제법, 주택건설촉진법, 항공법, 산업안전보건법 등에서 그 수준을 규제하고 있다 (KSNVE, 1995; Norsonic, 2013).

진동으로 인한 불편과 위험성을 평가하고 예방하기 위해 서는 진동을 정확하게 측정하고, 분석하는 것이 필요하다. 인간공학 분야에서는 진동에 관한 연구가 적고, 관련 문제를 다룰 때 진동 측정 장비가 제공하는 자료를 단순히 이용하여 특정 장비나 작업에서의 진동이 인체에 미치는 영향을 다루 는 것이 대부분이다(Cakmak et al., 2011; Goglia et al., 2003; Hermanns et al., 2008; Joshi, et al., 2012; Kumar, 2004; Smets et al., 2010). 본 소고에서는 인체진동의 종류 및 영향, 측정 장비, 측정 및 분석 방법, 주파수 가중 함수 등 인체진동의 전반을 정리하여, 추후 인체진동에 대한 연 구의 지침으로 제공하고자 한다.

\section{Human Vibration}

\subsection{Whole body vibration}

전신진동은 발, 엉덩이, 등 (back) 과 같은 장비 접촉 표면 을 통하여 전신으로 전달되는 경우를 말한다. 서론에서 언급 한 바와 같이 중량자동차, 버스, 승용차, 선박, 항공기 등의 운송수단, 건물, 공장의 대형 기계 등이 주진동원이다. 전신 진동에 장기간 노출되면 요통, 치질, 탈장과 같은 신체적 손 상과 더불어, 소화기계 및 비뇨기계 이상을 초래할 수 있다. 또한, 시각작업과 운동 수행 작업에 영향을 미쳐 작업 수행 도를 떨어뜨린다. 단기적으로는 피로감, 두통, 반응속도 저하, 메스꺼움, 불면증 등의 부작용을 유발할 수 있다(Bruel \& Kjar, 2001; Kee et al., 2006). 인체는 어떤 특정 주파수에 더 민감하게 반응하는 것으로 알려져 있으며, 사람에 따라 차이가 있으나 전신진동의 경우 $5 \sim 80 \mathrm{~Hz}$ 주위에서 가장 민 감하다(Norsonic, 2013; Sa, 2003).

전신진동은 측정 상황에 따라 세 가지 자세 즉, 앉은 자세, 선 자세, 누운 자세에서 측정된다. 진동 측정을 위하여 자세 에 따라 가슴, 의자 좌판, 발에 3 개의 좌표계, 9 개의 축이 정 의된다(Figure 1). 9 개의 각 축별로 병진 가속도와 앉은 자 세에서의 각축에서 3 개의 회전 가속도를 측정한다(National Instruments, 2013).

전신진동에 관한 표준은 다음의 2가지가 있다(KATS,
2011; Norsonic, 2013).

- ISO 2631 (Evaluation of human exposure to wholebody vibration) 혹은 KS B ISO 2631

- EU Physical Agents Directive(Vibration) 2002/44/ EC

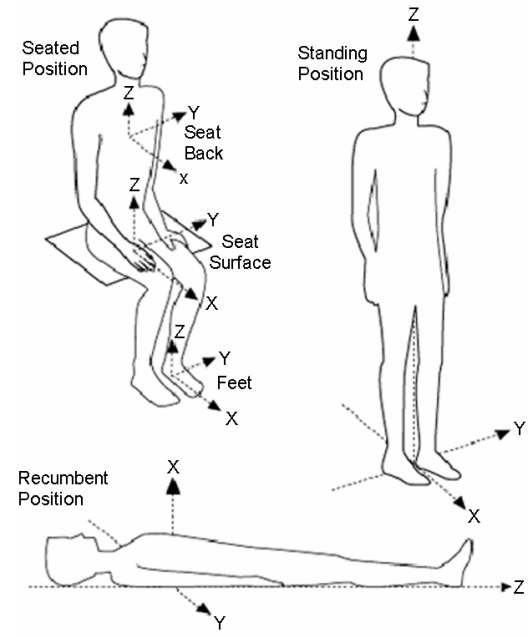

Figure 1. Three coordinate systems for whole-body vibration

\subsection{Hand-arm vibration}

전신 체계와 손-팔 체계는 동작자유도, 동작범위 등의 관 점에서 기계적으로 다르기 때문에 진동에서 두 체계는 별도 로 다루어진다. 손-팔 진동은 일상생활에서 자동차 운전 중 핸들로부터 전달되는 진동, 전동 수공구의 진동 등이 주원인 이다. 전신진동과 마찬가지로 장기간 노출되면 백지병과 같 은 영구적 신체 손상을 가져올 수 있고, 손목이나 팔의 관 절과 근육의 손상을 초래하기도 한다. 손-팔 진동의 경우 $5 \sim 1,500 \mathrm{~Hz}$ 에서 민감하다. 증상으로는 쑤심, 무감각, 열감, 추위에 과도한 반응 등을 들 수 있다(Bruel \& Kjar, 2001). 손-팔 진동을 측정하기 위하여 손이 쥐고 있는 물체에 중심 을 둔 기저중심(basicentric) 좌표계와 손등을 이용하는 생 체동역학(biodynamic) 좌표계가 정의된다(Figure 2).

손-팔 진동에 관한 표준은 다음의 2가지가 있다(KATS, 2004; Norsonic, 2013).

- ISO 5349 (Measurement and evaluation of human exposure to hand-transmitted vibration) 혹은 $\mathrm{KS}$ B ISO 5349

- EU Physical Agents Directive(Vibration) 2002/44/ $\mathrm{EC}$ 


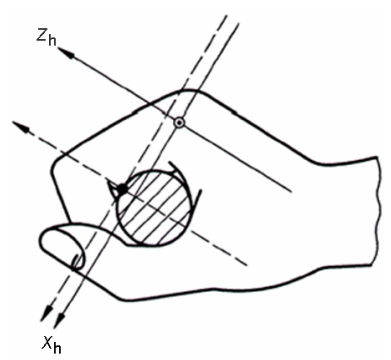

(a) Basicentric system

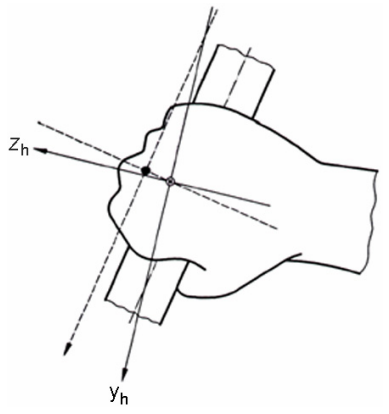

(b) Biodynamic system

Figure 2. Two coordinate systems in hand-arm vibration

\section{Measurement equipment}

\subsection{Mechanical vibration}

\subsubsection{Vibration level meter}

진동레벨계는 진동 공해의 평가에 관련된 지면진동의 측 정에 사용되는 공해용 진동레벨계와 일반기계, 전동공구 등 의 진동을 측정하기 위한 진동계 등 두 종류가 있다. 공해용 진동레벨계와 일반진동계는 필터단자에 진동 감각 보정회로 가 삽입되는지 여부에 따라 구분된다. 즉, 일반진동계의 필 터단자에 진동 감각 보정회로를 부착하면 공해용 진동레벨 계가 된다. 진동레벨계는 $\mathrm{KS} \mathrm{C} 1507$ 및 소음진동 공정 시 험법에 규정되어 있다(KSNVE, 1995).

\subsubsection{Vibration pick up}

기계계의 진동에너지를 전기에너지로 변환하는 장치를 진 동픽업이라 한다. 현재 사용되고 있는 진동픽업은 설치하는 방법에 따라 접촉형과 비접촉형으로 나누어 진다. 변환 출 력에 따라서는 가속도형, 속도형, 변위형으로 구분된다. 진 동 측정에 보편적으로 사용되는 변환기는 압전형 가속도계 (piezoelectric accelerometer)이다. 압전형 가속도계는 다 른 어떤 진동 측정 변환기(transducer)보다 모든 주파수 영
역에서 보다 좋은 특성과 안정성을 보인다. 또 매우 넓은 주 파수 범위와 그 영역에서의 좋은 선형성을 보유한 동적 범위 를 가지고 있으며, 비교적 튼튼하고 신뢰성이 높아 장기간 동안 특성이 변하지 않는다. 이 외에도 자가 발전을 하기 때 문에 전원이 필요하지 않고, 닪아 없어지는 움직이는 부품이 없고, 가속도로 나타나는 출력을 속도와 범위로 변환할 수 있도록 쉽게 적분할 수 있는 장점이 있다(KSNVE, 1995).

\subsubsection{Parameters of vibration}

물체가 진동하는 기계적 장치와 접하면 진동의 영향으 로 물체가 기준점으로부터 움직이게 된다. 이러한 변위 (displacement)의 크기로 진동의 크기를 나타낼 수 있으며, 가속도 및 속도로도 나타낼 수 있다. 진동을 어느 변수로 나 타내든 진동의 모양 및 주기가 같으며, 단지 위상만 다르다 (KSNVE, 1995).

\subsubsection{Quantification of vibration}

진동을 나타내는 매개변수인 변위, 가속도, 속도 중 대부 분의 진동 측정 장비는 가속도를 기본적으로 사용하고 있다. 가속도로부터 변위, 속도와 같은 다른 매개변수를 구할 수 있으며, 진동 측정 장비는 세 가지 매개변수를 서로 변환하 여 주는 기능을 갖추고 있다. 가속도의 단위는 $\mathrm{m} / \mathrm{s}^{2}$ 이며, 다 음 식을 이용하여 $10^{-6} \mathrm{~m} / \mathrm{s}^{2}$ 이 $\mathrm{OdB}$ 이 되도록 데시벨 단위로 변환할 수 있다(Bruel \& Kjar, 2001).

$$
\begin{aligned}
& \mathrm{L}(\mathrm{dB})=20 \log _{10}\left[\mathrm{a} / \mathrm{a}_{\mathrm{ret}}\right] \\
& \text { 여기서 } \mathrm{L} \text { : 진동 레벨 }(\mathrm{dB}) \text {, } \\
& \mathrm{a} \text { : 측정된 가속도 }\left(\mathrm{m} / \mathrm{s}^{2}\right) \text {, } \\
& \mathrm{a}_{\text {ret }} \text { : 진동 기준 레벨 }\left(10^{-6} \mathrm{~m} / \mathrm{s}^{2}\right) \text {. }
\end{aligned}
$$

진동 측정 장비로부터 측정된 순간 가속도는 시간 영역 (time domain) 즉, 측정 시간을 $\mathrm{x}$ 축으로 하는 2 차원 좌표에

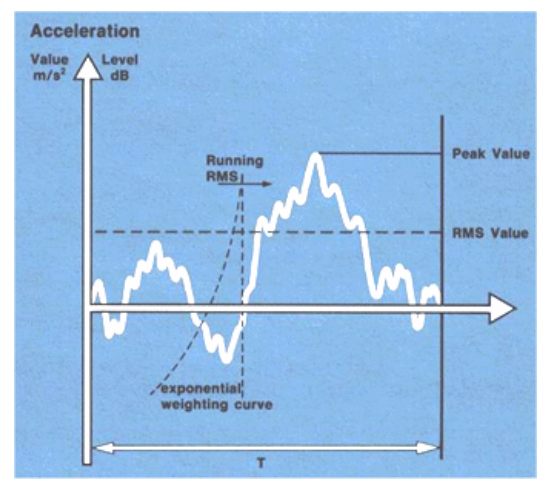

Figure 3. Plot of acceleration against time 
나타낼 수 있다(Figure 3). 이러한 진동은 여러 가지 값으로 요약될 수 있다.

\section{$\underline{\text { Peak value }}$}

피크값은 측정 시간 동안 측정된 순간 최대 가속도이다. 짧은 시간의 충격의 크기는 나타내는 데 좋은 척도이다.

\section{$\underline{\text { Peak-peak value }}$}

피크-피크값은 진동파의 최대 변화를 나타내는 데 적절 하다.

\section{$\underline{\text { RMS (root mean square) value }}$}

$\mathrm{RMS}$ 값은 진동 측정 시간 동안 측정된 순간 가속도 제곱 합(sum of squares) 평균의 제곱근으로, 다음 식으로 계산 된다. RMS값이 1 분 또는 1 시간과 같이 긴 시간 동안 계산 되어지면 측정된 진동의 에너지 정도를 나타내는 가속도가 되며, 이를 등가속도값(equivalent acceleration value) $\mathrm{a}_{\mathrm{eq}}$ $\left(\mathrm{m} / \mathrm{s}^{2}\right)$ 또는 등가속도레벨 (equivalent acceleration level) $\mathrm{L}_{\mathrm{eq}}(\mathrm{dB})$ 로 표기한다. 등가속도값 또는 등가속도레벨을 측 정 시간 동안 계속적으로 적용하면 원래의 다양하게 변하는 진동과 같은 영향을 가지게 된다.

$$
\text { RMS value }=\mathrm{a}_{\mathrm{eq}}=\sqrt{\frac{1}{T} \int_{0}^{T} a^{2}(t) d t}
$$

1 초 정도의 짧은 시간 간격으로 계산한 RMS값은 순간 또 는 'running' RMS값이라 한다. 순간 RMS값을 계산할 때 측정된 순간 가속도는 지수적으로 시간-가중 즉, 최근 측정 된 가속도에 이전에 계산된 가속도보다 더 큰 가중치를 주게 된다(Griffin, 1990; Bruel \& Kjar, 2001).

\subsection{Human vibration}

ISO 2631에서는 진동 수준을 가속도로 측정하도록 권장 하고 있다. 건물이나 배에서와 같이 매우 낮은 주파수와 낮 은 진동 크기를 가질 경우에는, 먼저 속도를 측정한 후 가속 도로 변환하도록 규정하고 있다(KATS, 2011).

ISO에서는 진동 분석 시 주파수 가중(frequencyweighted) 가속도를 사용할 것을 권장하고 있다(Cakmak et al., 2011; Goglia et al., 2003). 주파수 가중 가속도로 변환해 주는 필터를 부착한 다양한 인체진동 측정 장비가 상 용화되어 있어, 이를 이용하면 쉽게 주파수 가중 가속도를 구할 수 있다. 상용화되어 있는 가속도계는 제품에 따라 한 개에서 여러 개의 주파수 가중 함수가 구현된 필터를 장착하
고 있다. 따라서 어떤 주파수 가중 함수를 사용할 것인가에 따라 적절한 가속도계를 선택하여 사용하여야 한다.

인체진동 평가에 일반적으로 사용되는 매개변수들은 다음 과 같다.

\section{Frequency-weighted acceleration}

주파수 가중 가속도는 다음과 같이 구한다.

$$
\begin{aligned}
& \mathrm{a}_{\mathrm{w}}=\left[\sum_{i}\left(w_{i} a_{i}\right)^{2}\right]^{1 / 2} \\
& \text { 여기서 } \mathrm{a}_{\mathrm{w}} \text { : 주파수 가중 가속도, } \\
& \mathrm{w}_{\mathrm{i}} \text { : i번째 } 1 / 3 \text { 옥타브 대역에 대한 가중 요소(주파 } \\
& \quad \text { 수 가중 함수 및 주파수에 따라 다르며 관련 } \\
& \text { ISO 표준에 값이 제시되어 있음), }
\end{aligned}
$$

$\mathrm{a}_{\mathrm{i}}$ : i번째 $1 / 3$ 옥타브 영역에 대한 RMS 가속도.

ISO 5349에서는 손에 전달된 진동의 크기를 나타낼 때 RMS 주파수 가중 가속도(root-mean square frequencyweighted acceleration) $\left(\mathrm{m} / \mathrm{s}^{2}\right)$ 를 사용할 것을 권장하고 있 고, 실제 인체진동에 관한 인간공학 분야의 대부분의 연구 에서 이 값을 사용하고 있다(Cakmak et al., 2011; Goglia et al., 2003; Hermanns et al., 2008; Joshi et al., 2012; McCalling et al., 2010; Smets et al., 2010). 이 값은 안락 도 혹은 승차감 지수 및 보건 한계 설정에 사용된다(Cheung, 2010). 인간의 진동 인식 한계는 측정 축별 주파수 가중 함 수를 적용한 진동 신호의 피크값으로 정의하며, 인식 한계는 $0.015 \mathrm{~m} / \mathrm{s}^{2}$ 피크값으로 정하고 있다(Cheung, 2010). RMS 주파수 가중 가속도와 더불어 진동 신호를 시간 영역에서 주 파수 영역으로 변환하는 주파수 스펙트럼 분석도 병행되어 야 한다(Cakmak et al., 2011; Goglia et al., 2003).

\section{Crest factor}

파고율(crest factor)은 피크값과 총 측정 시간 동안에 걸쳐 계산된 $\mathrm{RMS}$ 값과의 비율로 정의된다. 진동이 충동적 (impulsive)이거나 랜덤할수록 파고율 값은 커진다. 충동적 (impulsive) 진동이 비충동적 진동에 비하여 건강에 해로운 것으로 알려져 있기 때문에, 파고율은 진동이 건강에 해로운 정도를 나타내는 좋은 척도가 된다(Griffin, 1990; Bruel \& Kjar, 2001).

$$
\text { Crest factor }=\frac{\text { Peakvalue }}{\text { RMSvalue }}
$$

어떤 진동 신호에 하나의 순간 충격(shock)이 발생하면, 파고율은 증가하나 RMS값은 크게 영향을 받지 않는다. 이 
러한 이유로 파고율이 RMS 평균값의 적용 가능성 (applicability)을 평가하는데 유용하게 사용된다. 즉, 전신진동에 서 파고율은 $\mathrm{RMS}$ 값이나 다른 분석 기법이 적절한지를 가 리키는 척도로 종종 사용된다(Mansfield, 2005) 파고율이 9 이하(ACGIH(American Conference of Governmental Industrial Hygienists) 와 BS 6841에서는 6을 사용)이면 주파수 스펙트럼 분석, RMS 주파 가중 가속도 계산 등 기 본적인 분석을 수행하면 대상 진동의 특성을 분석할 수 있 다. 그러나, 파고율이 9 를 초과하면 이러한 높은 크기의 진 동이 건강에 미치는 영향이 커지고, 주파수 가중 RMS 가 속도만으로는 높은 진동의 존재를 반영하기 어렵기 때문에 추가적 평가 방법을 사용하여야 한다(KATS, 2011; Kumar, 2004; Smets, et al., 2010). 이 때 올바른 분석 방법을 선 택하기 위해서는 세 평면 모두에서 파고율을 계산하여야 한 다(Kumar, 2004). 손-팔 진동에서는 모든 표준적 분석 방 법에서 RMS값이 사용되기 때문에 파고율은 많이 사용되지 않는다(Mansfield, 2005).

추가적인 방법으로 4제곱(fourth power) VDV (vibration dose value)를 사용하기도 한다. VDV는 진동 크기와 불편 도는 4제곱 관계에 있다는 연구 결과를 바탕으로 개발되었 다(Stevens, 1957; Mansfield, 2005). 다음 식에서 보는 바와 같이 주파수 가중 가속도의 지수가 4 로 되어 있어 진 동이 높게 튈 경우 낮은 진동에서 보다 더 크게 $\mathrm{VDV}$ 값에 반영된다. $\mathrm{VDV}$ 값은 $\mathrm{RMS}$ 값보다 순간 충격을 잘 반영하며, 그 값이 측정 기간 동안 계속 누적되어 가므로 낮은 진동 혹 은 진동이 없을 때에도 줄어들지 않는다(Mansfield, 2005). $\mathrm{VDV}$ 값은 전신진동에만 적용되며 안락도 혹은 승차감 지수, 인간의 기본 활동성 한계, 보건 한계 설정에 사용되고 있다 (Cheung, 2010). 순간 RMS값을 추가적 평가 방법으로 사 용하기도 한다(KATS, 2011; Smets et al., 2010).

$$
\mathrm{VDV}=\sqrt[4]{\int_{0}^{T} a_{w}^{4}(t) d t}\left(m s^{-1.75}\right)
$$

\section{Whole-body transmitted vibration for a day}

진동 피폭의 평가는 8시간 동안의 등가의 연속적인 가속 도로 표현되는 1 일 피폭진동 $\mathrm{A}(8)$ 의 계산을 기반으로 한다 (KATS, 2011).

$$
\mathrm{A}_{\mathrm{l}}(8)=\mathrm{k}_{\mathrm{l}} \sqrt{\frac{1}{T_{0}} \sum_{i} a^{2}{ }_{w l i} T_{i}}
$$

여기서 $\mathrm{a}_{\mathrm{wli}}$ : 주파수 가중치가 적용된 가속도의 RMS값 으로 시간 구간 $\mathrm{T}_{\mathrm{i}}$ 에 의해 결정됨,

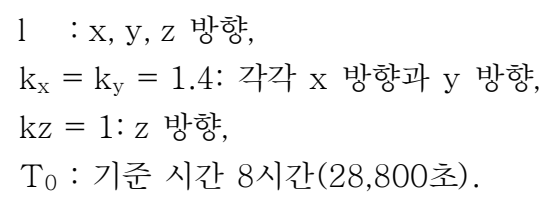

Hand-arm transmitted vibration for a day

일일 진동 노출 $\mathrm{A}(8)$ 은 다음과 같이 구하여 진다(KATS, 2011).

$$
\begin{aligned}
& \begin{aligned}
& \mathrm{A}(8)=\sqrt{\frac{1}{T_{0}} \sum_{i} a^{2}{ }_{h v i} T_{i}} \\
& \text { 여기서 } \mathrm{a}_{\mathrm{hvi}}:= \sqrt{a^{2}{ }_{h w x}+a^{2}{ }_{h w y}+a^{2}{ }_{h w z}}: \mathrm{i} \text { 번째 작동에 } \\
& \text { 의한 진동 총값, } \mathrm{a}_{\mathrm{hwx}}, \mathrm{a}_{\mathrm{hwy}}, \mathrm{a}_{\mathrm{hwz}} \text { 는 } \mathrm{x}, \mathrm{y}, \\
& \mathrm{Z} \text { 축 가중 } \mathrm{RMS} \text { 가속도 값임, }
\end{aligned}
\end{aligned}
$$

$\mathrm{T}_{\mathrm{i}}$ : i번째 작동 시간.

\section{Composite vibration}

한 방향 이상의 복합진동은 직교 좌표축의 RMS 주파수 가중 가속도의 가중합으로 다음과 같이 구한다. $\mathrm{a}_{\mathrm{v}}$ 는 진동값 으로 안락도 평가에 사용된다(KATS, 2011).

$$
\mathrm{a}_{\mathrm{v}}=\left(\mathrm{k}_{\mathrm{x}}{ }^{2} \mathrm{a}_{\mathrm{wx}}{ }^{2}+\mathrm{k}_{\mathrm{y}}{ }^{2} \mathrm{a}_{\mathrm{wy}}{ }^{2}+\mathrm{k}_{\mathrm{z}}{ }_{\mathrm{z}} \mathrm{a}_{\mathrm{wz}}{ }^{2}\right)^{1 / 2}
$$

여기서 $\mathrm{a}_{\mathrm{wx}}, \mathrm{a}_{\mathrm{wy}}, \mathrm{a}_{\mathrm{wz}}$ : 직교축 $\mathrm{x}, \mathrm{y}, \mathrm{z}$ 각각에 대한 $\mathrm{RMS}$ 주파수 가중 가속도,

$\mathrm{k}_{\mathrm{x}}, \mathrm{k}_{\mathrm{y}}, \mathrm{k}_{\mathrm{z}} \quad$ : 곱셈인자(적용된 주파수 가중 함수 에 따라 다르며 관련 ISO 표준에 제시되어 있음).

\section{Evaluation of instantaneous shock}

ISO 2631에서는 순간 충격과 같은 진동 신호를 평가하 기 위하여 새로운 평가치들을 정의하고 있다(KATS, 2011). 즉, 매 1 초마다 연속으로 측정된 RMS값 중 최대 과도 진 동값(maximum transient vibration value: MTVV) 과 측 정 시간 시작에서 종료까지 가중화된 진동 신호 제곱의 합 인 MSDV (motion sickness dose value) 가 있다(Cheung, 2010).

\section{Frequency Weighting}

\subsection{Natural frequency of human body}

진동은 기계의 움직이는 부분에서 발생하고 이 부분과 접 하고 있는 인체에 전달된다. 모든 움직이는 부분은 그 움직 
임과 관련된 주파수를 가지고 있으며, 인체에 전달되는 진동 은 여러 주파수로 구성되어 있는 것이 일반적이다. 인체는 주파수에 따라 수용 민감도가 다르기 때문에 주파수 가중이 필요하다(Bruel \& Kjar, 2001; Sa, 2003).

인체 부위별 고유 진동수는 다음 Table 1 에 나와 있으며, 고유 진동수와 같은 진동이 전달되면 공진 현상이 일어난다. 따라서 인체진동을 평가할 때 언급한 방화 같이 진동의 주파 수가 고려되어야 한다. 또한, 인체는 좌우 대칭이 아니기 때 문에 진동의 방향이 중요하게 되며, 주파수 가중 시 방향이 고려되어야 한다(Bruel \& Kjar, 2001). 이를 반영하여 ISO 에서는 전신진동의 경우 두 가지 방향 즉, 수직 방향 $(z$ 축 $)$ 과 수평 방향 $(\mathrm{x}, \mathrm{y}$ 축)에 대한 주파 가중 곡선을 제시하고 있다.

Table 1. Natural frequency of human body $(\mathrm{Hz})$

\begin{tabular}{c|c|c|c}
\hline Body part & Frequency & Body part & Frequency \\
\hline Eyeball & $20 \sim 90$ & Chest & $50 \sim 60$ \\
\hline Head & $20 \sim 30$ & Arm & $5 \sim 10$ \\
\hline Shoulder & $4 \sim 5$ & Hand & $30 \sim 50$ \\
\hline Lower arm & $16 \sim 30$ & Abdominal mass & $4 \sim 8$ \\
\hline Spinal column & $10 \sim 12$ & Leg & $2 \sim 20$ \\
\hline
\end{tabular}

\subsection{Frequency weighting}

\subsubsection{Necessity of frequency weighting}

기계적 진동에 대한 인체의 민감도는 진동의 주파수 및 방 향에 영향을 받는다. 즉, 전신진동이 건강, 안락도, 인지 및 멀미에 미치는 일차적 인자는 피폭진동의 주파수이며, 다음 으로 피폭진동의 위치와 축 방향이 된다. 따라서 진동이 인 체에 미치는 영향을 바르게 평가하기 위해서는 기계진동의 측정값을 그대로 사용하여서는 안되며, 기계진동의 값을 주 파수 및 방향에 대한 인체의 민감도를 반영한 주파수 가중 된 (frequency-weighted) 값을 사용하여야 한다(Bruel \& $\mathrm{Kjar}, 2001)$. 예를 들어, 앉아있는 사람은 $100 \mathrm{~Hz}$ 에서보다 $5 \mathrm{~Hz}$ 진동에서 10 배나 더 민감하다. 두 진동 사이의 주관적 감각의 등가성 (parity)을 유지하기 위해서는 $100 \mathrm{~Hz}$ 의 진동 은 $5 \mathrm{~Hz}$ 진동과 비교할 때 $1 / 10$ 정도로 줄여주어야 한다. 이 를 반영하는 다수의 주파수 가중 함수가 개발되어 있다. 주 파수 가중 함수는 인체가 가장 민감한 주파수 영역의 진동 은 그대로 두고, 인체가 덜 민감한 주파수 영역의 진동의 크 기를 감소시키는(attenuate) 방향으로 만들어진다. 주파수 가중이 진동 신호를 증폭시키지는 않기 때문에 주파수 가중 된 신호의 크기는 원진동 신호에 비하여 커지지는 않는다. 인체진동에서는 진동원의 기계적 특성보다는 진동에 대한
인체의 반응을 나타낼 수 있도록 주파수 가중 함수를 기계 적으로 측정된 시간 영역 진동 신호에 적용한다(Mansfield, 2005).

ISO에서는 전신진동의 경우 건강, 안락도, 인지 및 멀미와, 손-팔 진동에서는 백지병과 노출진동과의 관계를 바탕으로 여러 주파수 가중 함수를 제시하고 있다. 예를 들어, ISO에 서 제안한 손-팔 진동에 대한 주파수 가중 함수 $\mathrm{wh}_{\mathrm{h}}$ 는 진동 에 노출된 집단의 $10 \%$ 가 백지병에 걸린다는 가정 하의 하 루 진동 전달량 $\mathrm{A}(8)$ 과 진동 노출 기간과의 선형 관계를 바 탕으로 개발되었다(Bovenzi et al., 2011).

이상에서 살펴본 바와 같이 가속도계로부터 측정되는 기 계적 진동값을 그대로 사용할 경우, 인간이 주관적으로 느끼 는 진동 레벨을 제대로 반영하지 못하게 된다. 또한, 진동 노 출로 인한 요통, 백지병과 같은 부작용의 발생 확률 및 강도 를 제대로 평가하지 못하게 된다.

현재 사용되고 있는 주파수 가중 함수는 다음과 같은 한계 가 있어 사용 시 주의가 필요하다. 첫째, 주파수 가중법은 등 감각 곡선(equal sensation curve)을 다루는 연구의 분석을 기반으로 유도되어, 개개인보다는 어떤 집단의 특성을 반영 하고 있다. 즉, 개인 간 또는 개인 내 차이가 충분히 반영되 지 못한다. 둘째, 인체의 진동 감각의 선형성(linearity)을 가정하여 진동의 높고 낮음에 관계없이 하나의 주파수 가중 법만 사용된다. 그러나 매우 낮은 진동에서는 주파수 가중법 으로 예측하는 것보다 진동에 대한 인체의 감각이 빠르게 증 가하는 것으로 알려져 있다(Howarth and Griffin, 1988). 셋째, 진동의 지각이나 안락도의 평가로 상해를 예측하고 있 으나, 이러한 생리적 반응이 감각되는 곳과 진동으로 인한 상해가 발생하는 곳이 다를 수 있다. 즉, 진동의 주관적 생 리적 반응과 상해 발생 가능성이 다를 수 있다(Mansfield, 2005).

\subsubsection{Whole-body vibration}

전신진동은 심장을 원점으로 하는 직교 좌표계의 세 방향 으로 측정되어야 한다. 진동에 대한 인체 반응은 전후 방향 (x축) 과 좌우 방향 (y축) 즉, 횡단면(transversal plane)에 서는 차이가 없는 것으로 알려져 있다(Bruel \& Kjar, 2001; $\mathrm{KATS}, 2011)$. ISO에서는 측면 방향 (x, y축) 과 수직 방향 ( $\mathrm{z}$ 축) 에 대한 전신진동의 주파수 가중 곡선을 각각 제시하 였다. 가중된 진동은 측정된 진동 수준과 진동으로 인한 주 관적 느낌이나 충격 (impact) 사이의 관계를 잘 설명해주게 된다(Bruel \& Kjar, 2001).

ISO에서는 전신진동 및 손-팔 진동에 대한 9 개의 주파수 가중 함수를 제시하고 있다(Figure 4, Table 2). ISO 2631 및 5349에서는 각 주파수에 대한 가중인자를 주파수 가중 함수별로 표로 제시하고 있다(KATS, 2011). 전신진동에서 
는 $\mathrm{W}_{\mathrm{b}}, \mathrm{W}_{\mathrm{d}}, \mathrm{W}_{\mathrm{k}}$, 손-팔 진동에서는 $\mathrm{W}_{\mathrm{h}}$ 가 가장 많이 사용 된다(Mansfield, 2005).

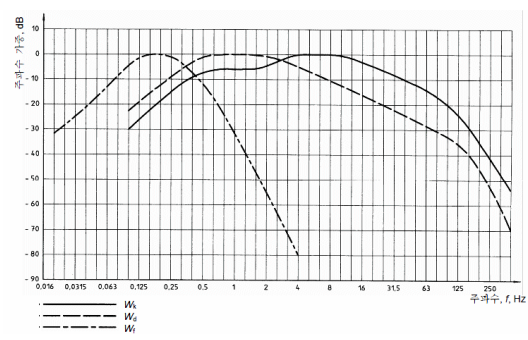

(a) Main frequency weighting curves

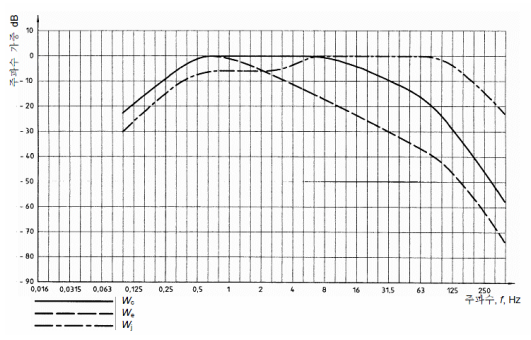

(b) Added frequency weighting curves

Figure 4. Frequency weighting curves for whole-body vibration by ISO

Table 2. Frequency weighting methods by ISO

\begin{tabular}{|c|c|c|c|}
\hline Weighting & Usage & Direction & Reference \\
\hline$W_{b}$ & $\begin{array}{c}\text { Vertical } \\
\text { whole-body } \\
\text { vibration }\end{array}$ & $\begin{array}{l}\text { z-axis, seated, } \\
\text { standing or } \\
\text { recumbent person }\end{array}$ & $\begin{array}{c}\text { ISO 2631-4, } \\
\text { BS } 6841\end{array}$ \\
\hline$W_{c}$ & $\begin{array}{l}\text { Horizontal } \\
\text { whole-body } \\
\text { vibration }\end{array}$ & $\begin{array}{l}\mathrm{x} \text {-axis, seat back, } \\
\text { seated person }\end{array}$ & ISO 2631-1 \\
\hline$W_{d}$ & $\begin{array}{l}\text { Horizontal } \\
\text { whole-body } \\
\text { vibration }\end{array}$ & $\begin{array}{l}\text { x- or y-axis, seated, } \\
\text { standing or } \\
\text { recumbent person }\end{array}$ & ISO $2631-1$ \\
\hline$W_{e}$ & $\begin{array}{c}\text { Rotational } \\
\text { whole-body } \\
\text { vibration }\end{array}$ & $\begin{array}{l}\text { All directions, } \\
\text { seated person }\end{array}$ & ISO 2631-1 \\
\hline$W_{f}$ & $\begin{array}{c}\text { Vertical } \\
\text { whole-body } \\
\text { vibration }\end{array}$ & $\begin{array}{l}\text { z-axis motion } \\
\text { sickness, seated or } \\
\text { standing person }\end{array}$ & ISO 2631-1 \\
\hline$W_{h}$ & $\begin{array}{l}\text { Hand-arm } \\
\text { vibration }\end{array}$ & All directions & ISO 5349-1 \\
\hline$W_{j}$ & $\begin{array}{c}\text { Vertical head } \\
\text { vibration, motion } \\
\text { sickness }\end{array}$ & $\begin{array}{l}\mathrm{x} \text {-axis recumbent } \\
\text { person }\end{array}$ & ISO $2631-1$ \\
\hline
\end{tabular}

Table 2. Frequency weighting methods by ISO (Continued)

\begin{tabular}{c|c|c|c}
\hline Weighting & Usage & Direction & Reference \\
\hline$W_{k}$ & $\begin{array}{c}\text { Vertical } \\
\text { whole-body } \\
\text { vibration }\end{array}$ & $\begin{array}{c}\text { z-axis seated, } \\
\text { standing or } \\
\text { recumbent person }\end{array}$ & $\begin{array}{c}\text { ISO 2631-1, } \\
\text { EU Physical } \\
\text { Agents Directive }\end{array}$ \\
\hline$W_{m}$ & $\begin{array}{c}\text { Whole-body } \\
\text { vibration in } \\
\text { buildings }\end{array}$ & All directions & ISO 2631-2 \\
\hline
\end{tabular}

\subsubsection{Hand-arm vibration}

손-팔 진동에서는 진동에 대한 인체의 반응이 모든 방향 에서 같기 때문에, 하나의 주파수 가중 곡선만 있으면 된다 (Goglia, 2003; KATS, 2004). ISO는 손-팔 진동에 대한 주파수 가중 곡선 $\left(\mathrm{W}_{\mathrm{h}}\right)$ 을 제시하고 있으며, 곡선에서 12 $16 \mathrm{~Hz}$ 사이에서 인체가 가장 민감하게 반응함을 볼 수 있다 (Figure 5).

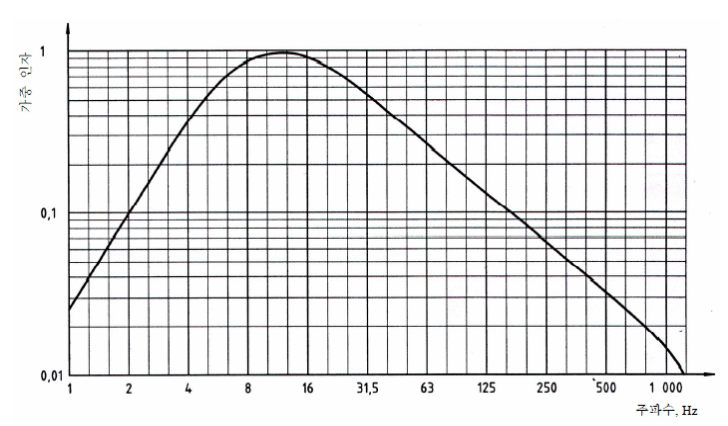

Figure 5. Frequency weighting curve for hand-arm vibration by ISO

\subsubsection{Researches on frequency weightings}

정확한 주파수 가중 함수를 개발하기 위해서는 진동 노출 과 이로 인한 건강장해, 작업 수행도 감소 등과 같은 부작용 과의 관계가 우선적으로 밝혀져야 하나, 그 관계가 아직 완 전히 밝혀지지 않았다. 좀 더 구체적으로 살펴보면, 손-팔 의 혈관, 감각신경, 근골격계 장애를 통칭하는 손-팔진동증 후군(hand-arm vibration syndrome: HAVS)을 유발할 확률과 진동 노출의 관계도 아직 충분히 알려져 있지 않다 (Dong et al., 2006). 따라서 손-팔 진동 평가에 어떤 척도 가 진동 노출의 심각성을 정량화하는 데 가장 좋은 지는 불 명확하나, ISO에서는 주파수 가중 가속도를 사용할 것을 권 장하고 있다. 그러나 주파수 가중 가속도가 관련 상해나 장 애를 유발하는 위험성을 정확하게 반영하지 못할 수도 있다. 이는 가중 주파수 가속도에 기반한 ISO의 예측 결과와 일치 
하는 역학적 연구는 소수인 반면, 다수의 연구는 큰 차이를 보이고 있는 사실에서 알 수 있다(Bovenzi et al., 2011; Dong et al., 2006). ISO 5349에서 제안하고 있는 주파수 가중 함수 $\mathrm{W}_{\mathrm{h}}$ 는 진동에 대한 손가락의 생리학적 또는 생체 동역학적(biodynamic) 반응의 주파수 의존성(frequencydependence) 을 반영하지 못한다는 것이 실험을 통하여 알 려져 있다(Bovenzi et al., 2000; Dong et al., 2004, 2005, 2007). 또한, ISO에서 여러 주파수 가중 함수를 제안할 때 기반한 기존 연구의 실험 조건(예: 노출진동의 주파수, 피실 험자 등) 과 다른 진동에 노출될 경우 기존 주파수 가중 함수 를 사용하는 데 한계가 있다. 이러한 연구 결과를 바탕으로 ISO에서 제안한 주파수 가중 함수 이외의 새로운 주파수 가 중법을 개발하고 이를 검증하는 연구가 이루어져 오고 있다 (Bovenzi et al., 2011; Brammer and Pitts, 2012; Dong et al., 2006; Giacomin et al., 2004; Tominaga, 2005). ISO 에서도 ISO TC 108/SC 4의 working group(WG 3)에서 기계진동과 충격의 인체 노출에 관한 다수의 새로운 주파수 가중법이 검토되고 있다(Bovenzi et al., 2011).

이상에서 살펴본 바와 같이 새로운 주파수 가중법을 개발 하는 연구는 손-팔 진동에 관한 것이 대부분이었다. 반면, Kim et al. (2009)은 신체 부위, 근골격 및 세포 조직의 특성 과 모양이 서양인과 다른 아시아인(특히, 한국인)에 적절한 전신진동 주파수 가중 함수를 개발하였다.

이 외에 Ishitake et al.(2002)은 위운동에 대한 ISO에 서 제안한 전신진동 주파수 가중법의 적절성 평가, Rimell과 Mansfield(2007)는 주파수 가중법을 위한 디지털 필터 설 계, Radwin et al. (1990)은 촉감에 대한 손-팔의 주파수 가중 진동의 영향을 다루는 연구를 수행하였다.

\section{Vibration Measurement}

\subsection{Vibration measurement system}

진동 측정의 정확성은 진동 변환기와 분석 및 기록 장비에 영향을 받는다. 크기 및 무게가 아주 다양한 가속도계가 상 용화 되어 있기 때문에 가속도계 부착이 측정값에 영향을 주지 않고, 손-팔 진동 측정 시는 피측정자의 공구 쥐는 자 세를 방해하지 않는 가속도계를 선정하여야 한다. 이와 더불 어 가속도계를 선택할 때 가속도계의 감도, 동적 범위를 고 려하여야 하며, 인체진동을 측정할 때는 측정 목적에 맞는 주파수 가중 함수가 구현되어 있는 필터가 갖추어져 있는 지 를 확인하여야 한다(Griffin, 1990; Bruel \& Kjar, 2001).

인체진동은 일반적으로 다음과 같은 순서로 측정, 기록된 다(Figure 6). 변환기를 가능한 최대한 진동 전달 지점에 가
까이 부착한 후 진동을 측정하며, 기계적으로 측정된 진동은 1 차 증폭 과정을 거친다. 이 증폭된 진동 신호를 용도에 맞 는 주파수 가중법을 이용하여 주파수 가중된 신호로 전환하 고, 이를 다시 2 차로 증폭한다. 2 차 증폭된 진동 신호는 표 시 장치를 통하여 아날로그 혹은 디지털 신호로 출력되거나 저장장치에 저장된다.

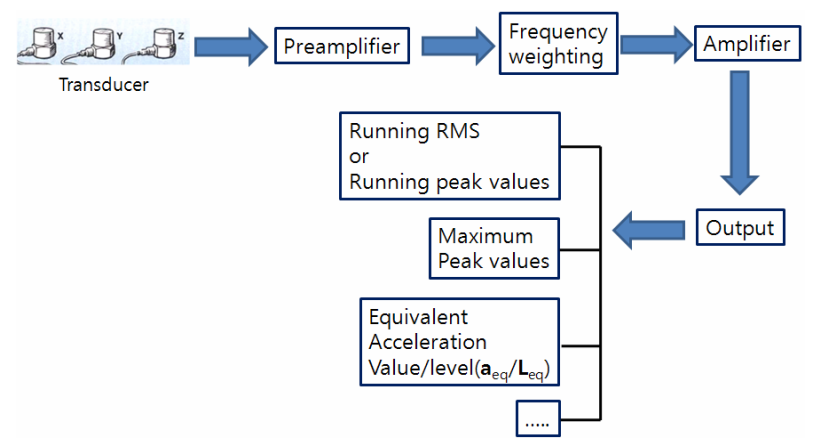

Figure 6. Diagram of vibration measurement system

\subsection{Vibration measurement}

\subsubsection{Whole-body vibration}

진동은 인체로 전달되는 부분에 가능하면 가까운 곳 즉, 인체와 진동원의 접촉부 사이의 표면에서 측정되어야 한다. 이를 위하여 접시형 변환기가 사용될 수 있다(Figure 7 (a)). ISO 표준은 지지되는 시트 표면(엉덩이), 시트의 등 받침대, 그리고 발과 같이 앉아 있는 사람의 주된 3가지의 접촉면을 사용한다. 지지되는 시트 표면에서의 측정은 좌골의 융기 부 분 아래(즉, 엉덩이뼈 밑)에서 해야 한다. 시트의 등 부위에 서의 진동 측정은 상체를 주로 지지하는 부분에서 이루어져 야 한다. 발에서의 측정은 발을 가장 많이 지지하는 표면에 서 이루어져야 한다. ISO 표준에서는 누운 자세의 측정 위치 는 골반, 등 부위, 머리 아래의 지지되는 부분으로 정의하고 있다. 어떠한 경우에도 측정 위치는 명확히 표기되어야 한다.

측정 시간은 통계적 정확도를 보장할 수 있을 뿐 아니라, 평가 진동의 피폭량을 나타내기에 충분한 시간을 선정해야 하고, 반드시 표기되어야 한다. 전체 진동 피폭이 다수의 특 정 시간대들로 구성되어 있는 경우, 각각의 측정 시간들에 대한 분리된 분석 작업이 필요할 수 있다(KATS, 2011).

전신진동의 측정에 대해서는 ISO 2631, BS 6841, 바퀴 달린 농업용 트랙터와 농기계에 대해서는 ISO 5008, 철도 차량에 대해서는 ISO 10056에, 차량 의자 진동에 대해서는 ISO 10326에, 토목 기계 의자 진동에 대해서는 ISO 7096, 산업용 트럭 의자 진동에 대해서는 $\mathrm{EN} \mathrm{13490에} \mathrm{규정하고}$ 
있다(Mansfield, 2005).

\subsubsection{Hand-arm vibration}

진동원이 손에 쥐어져 있으면 손바닥을 통하여 손으로 진 동이 전달된다. 정확한 진동의 측정을 하기 위해서는 가속도 계를 손바닥과 진동원 사이에 설치하여야 하나, 아주 작은 가속도계를 사용하더라도 사용자의 공구 쥐기를 방해하여 정확한 측정을 어렵게 한다. 이를 방지하기 위하여 가속도계 를 공구 손잡이에 부착하는 방안을 고려할 수 있으나, 손잡 이는 대부분 둥근 형태로 되어 있어 부착이 어려운 문제가 있다(Bruel \& Kjar, 2001; KATS, 2004).

다른 방법으로 가속도계를 올려 놓을 수 있는 어댑터 (adapter)를 사용자의 작업을 방해하지 않는 곳에 부착하는 것을 들 수 있다(Figure 7 (b)). 가속도계의 설치와 휴대용 어댑터 사용에 대해서는 ISO 5348, KS B 5349-2에 규정 되어 있다.

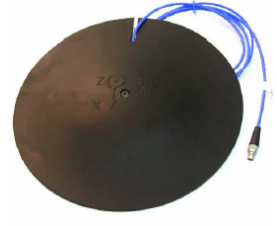

(a) Dish-type transducer

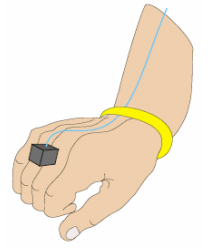

(b) Adapter for hand
Figure 7. Attaching transducers

손-팔 진동의 측정에 대해서는 ISO 5349, BS 6842에 일 반적인 것이 규정되어 있고, 손으로 다루는(hand-guided) 기계의 손잡이 표면 진동에 대해서는 $\mathrm{EN} \mathrm{1033에,} \mathrm{손으로}$ 운용하는 전동공구 손잡이 진동에 대해서는 ISO 8662에 그 측정 방법이 규정되어 있다(Mansfield, 2005).

\subsection{Statistical analysis and evaluation}

대부분의 상용화되어 있는 가속도계가 기본적으로 제공 하는 진동을 나타내는 피크값, RMS 주파수 가중 가속도와 같은 대표값으로 측정된 진동의 특성을 개략적으로 파악할 수 있다. 또한, 이러한 값을 통하여 ISO, ACGIH 등에서 제시한 노출 한계와의 비교를 통하여 위험성을 평가할 수 있다. Figure 8은 ISO의 전신진동 노출 한계 (whole body exposure limit), 피로-감소 능숙도 경계(whole body fatigue-decreased proficiency boundary), 안락도 감소 경계 (whole body reduced comfort boundary)를 나타내 고 있다(Bruel \& Kjar, 2001). 파고율이 9를 초과하면
$\mathrm{VDV}$ 와 같은 추가적인 평가치를 이용하여야 한다.

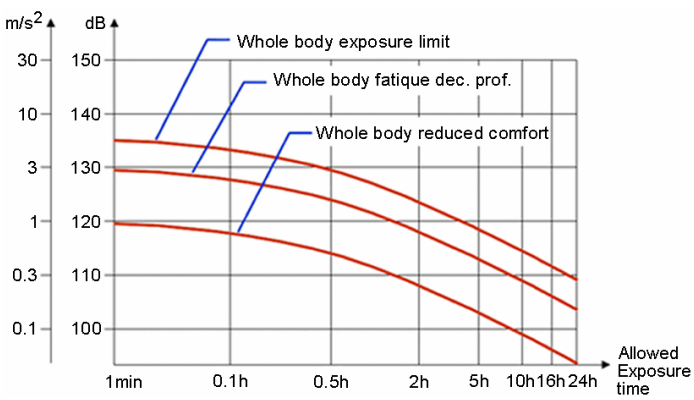

Figure 8. ISO dose system for whole-body vibration

OSHA에서 제시한 소음량(noise dose) 개념과 같이 등가 속도값/레벨을 이용하여 진동량(vibration dose)를 계산하 여 노출된 진동의 위험성을 평가할 수 있다(Bruel \& Kjar, 2001).

$$
\begin{aligned}
& \text { Dose }=\left(\mathrm{t}_{1} / \tau_{1}+\mathrm{t}_{2} / \tau_{2}+\mathrm{t}_{3} / \tau_{3}\right) \times 100 \% \\
& \text { Dose }=\left(\frac{t_{1}}{\tau_{1}}+\frac{t_{2}}{\tau_{2}}+\frac{t_{3}}{\tau_{3}}\right) \times 100 \%
\end{aligned}
$$

여기서 $\mathrm{t}$ : 특정 수준의 진동 노출 시간, $\tau$ : 특정 수준의 허용 시간.

예를 들어, 하루 동안 세 가지 작업에 다음 Table 3 과 같 이 노출되었을 때 진동량은 다음과 같다.

Table 3. Example of dose calculation

\begin{tabular}{c|c|c|c}
\hline Task & Elapsed time, $\mathrm{t}(\mathrm{hrs})$ & $\mathbf{a}_{\mathrm{eq}}\left(\mathrm{m} / \mathrm{s}^{2}\right)$ & Allowed time, $\tau(\mathrm{hrs})$ \\
\hline 1 & 2 & 0.7 & 2.5 \\
\hline 2 & 0.5 & 1.3 & 0.9 \\
\hline 3 & 1 & 0.3 & 8 \\
\hline
\end{tabular}

Dose $=(2 / 2.5+0.5 / 0.9+1 / 8) \times 100 \%=148.1 \%$

진동이 특정 구간(예: $\mathrm{L}(\mathrm{dB})$ 와 $\mathrm{L}(\mathrm{dB})+\Delta \mathrm{L}(\mathrm{dB})$ 사이) 에 있는 시간을 측정 기간에 대한 비율로 나타내는 확률분 포곡선을 그릴 수 있다(Figure 9). 이 곡선을 통하여 측정 기간 동안에 어떤 수준의 진동의 분포를 알 수 있다. Figure 10 은 $2 \mathrm{~dB}$ 간격으로 확률분포곡선을 나타내었으며, $97 \mathrm{~dB}$ 과 $99 \mathrm{~dB}$ 사이 소음은 전체 측정 시간의 약 $4 \%$ 를 차지하였음 을 알 수 있다. 


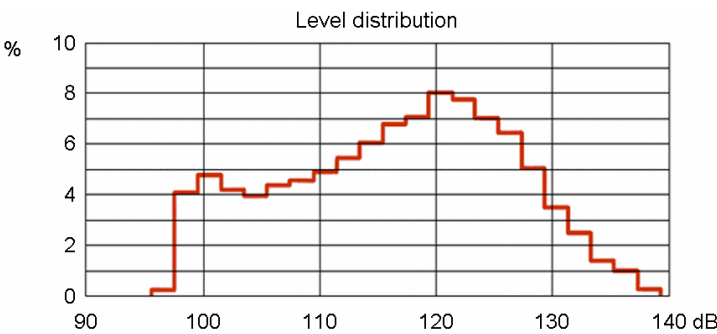

Figure 9. Probability distribution curve for exposed vibration

확률분포곡선을 이용하여 주어진 진동 수준을 초과하는 비율을 나타내는 누적확률분곡선을 그릴 수 있다(Figure 10). Figure 10 에서 $\mathrm{L} 10$ 즉, $128 \mathrm{~dB}$ 을 초과하는 비율이 총 측정 시간 중 $10 \%$ 임을, $\mathrm{L} 90103 \mathrm{~dB}$ 을 초과하는 비율은 $90 \%$ 임을 보이고 있다.

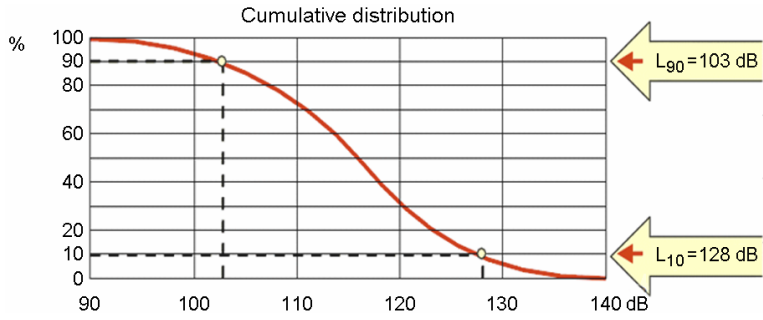

Figure 10. Cumulative distribution curve for exposed vibration

\section{Conclusion}

본 연구에서는 기계적 진동과 인체진동, 인체진동 측정 장 비와 매개변수, 주파수 가중법의 필요성 및 종류 등 인체진 동 측정에 대한 전반적 프로세스를 정리하였다. 주파수 가중 법에 대해서는 ISO에서 제안하고 있는 방법을 용도별로 정 리하고, 그 문제점 및 이를 해결하려는 연구들을 살펴보았다. 인체진동에 대한 주파수 가중법은 진동에 대한 인체의 주관 적 반응 및 요통, $\mathrm{VWF}$ 와 같은 건장장해와의 관계가 명확히 밝혀져야 좀 더 정확한 방법이 수립될 수 있을 것으로 판단 된다. 이를 위하여 다양한 인종, 연령, 성별, 진동 노출 경력 등을 고려한 피실험자, 노출 진동의 주파수를 다양화한 실험 적 및 임상학적 연구가 수행되어야 할 것이다.

\section{References}

Bovenzi, M., Lindsel,1 C.J. and Griffin, M.J., Acute vascular response to the frequency of vibration transmitted to the hand, Occupational Environmental Medicine, 57, 422-430, 2000.

Bovenzi, M., Pinto, I., Picciolo, F., Mauro, M. and Ronchese, F., Frequency weightings of hand-transmitted vibration for predicting vibration induced white finger, Scandinavian Journal of Work, Environment \& Health, 37(3), 244-252, 2011.

Brammer, A.J. and Pitts, P.M., Frequency weightings for vibration-induced white finger compatible with exposure-response models, Industrial health, 50, 397-411, 2012.

Bruel \& Kjar, Vibration \& noise-principle and practice, 2001

Cakmak, B., Saracoglu, T., Alayunt, F.N. and Ozarslan, C., Vibration and noise characteristics of flap type olive harvesters, Applied Ergonomics, 42, 397-402, 2011.

Cheung, W-S., An introduction to measurement and evaluation of wholebody vibration, Journal of KSNVE, 20(3), 13-19, 2010.

Dong, J.H., Dong, R.G., Rakheja, S, Welcome, D.E., McDowell, T.W. and Wu, J.Z., A method for analyzing absorbed power distribution in the hand and arm substructures when operating vibrating tools, Journal of Sound and Vibration, 311, 1286-1304, 2008.

Dong, R.G., Schopper, A.W., Mcdowell, W., Welcome, D.E., Wu, J.Z., Smuz, W.P., Warren, C. and Rakheja, S., Vibration energy absorption (VEA) in human fingers-hand-arm system, Medical Engineering \& Physics, 26, 483-492, 2004.

Dong, R.G., Welcome, D.E., Mcdowell, W., Wu, J.Z. and Schopper, A.W., Frequency weighting derived from power absorption of fingershand-arm system under $\mathrm{z}_{\mathrm{h}}$-axis vibration, Journal of Biomechanics, 39, 2311-2324, 2006

Dong, R.G., Welcome, D.E. and Wu, J.Z., Frequency weightings based on biodynamics of fingers-hand-arm system, Industrial Health, 43, 516 $-526,2005$.

Giacomin, J., Shayaa, M.S., Dormegnie, E. and Richard, L., Frequency weighting for the evaluation of steering wheel rotational vibration, International Journal of Industrial Ergonomics, 33, 527-541, 2004.

Goglia, V., Gospodaric, Z., Kosutic, S. and Filipovic, D., Hand-transmitted vibration from the steering wheel to drivers of a small four-wheel drive tractor, Applied Ergonomics, 34, 45-49, 2003.

Griffin, M.J., Handbook of human vibration, Academic press, 1990.

Hermanns, I., Raffler, N., Ellegast, R.P., Fischer, S. and Gores, B., Simultaneous field measuring method of vibration and body posture for assessment of seated occupational driving tasks, International Journal of Industrial Ergonomics, 38, 225-263, 2008.

Howarth, H.V.C. and Griffin, M.J., The frequency dependence of subjective reaction to vertical and horizontal whole-body vibration at low magnitude, Journal of the Acoustical Society of America, 8394, 1406 $-1413,1988$

Ishitake, T., Miyazaki, Y., Nogucji, R., Ando, H. and Matoba, T., Evaluation of frequency weighting (ISO 2631-1) for acute effects of whole-body vibration on gastric motility, Journal of Sound and Vibration, 253(1) 
31-36, 2002.

Joshi, A., Leu, M. and Murray, S., Ergonomic analysis of fastening vibration based on ISO Standard 4349(2001), Applied Ergonomics, 43, 1051 $-1057,2012$,

KATS, Mechanical vibration-Measurement and evaluation of human exposure to hand-transmitted vibration-Part I: General requirements (KS B ISO 5349-1:2011), 2004

KATS, Mechanical vibration and shock-Evaluation of human exposure to whole-body vibration-Part I: General requirements (KS B ISO 2631-1: 2011), 2011.

Kee. D., Park, J.H., Lee, K.T. and Choi, K.I., Ergonomics for industrial safety and health manager, Hankyungsa, 2006.

Kim, K-W., Kim, M-S. and Yoo, W-S., Development of frequency weighting function for Asian (Korean) people in vertical whole-body vibration; in comparison with ISO 2631-1, Journal of Mechanical Science and Technology, 23, 2738-2746, 2009.

KSNVE (The Korean Society for Noise and Vibration Engineering), Handbook of noise and vibration, 1995.

Kumar, S., Vibration in operating heavy haul tricks in overburden mining, Applied Ergonomics, 35, 509-520, 2004.

Mansfield, N.J., Human response to vibration, CRC press, 2005.

McCalling, M., Paddan, G., Lente, E.V., Moore, K. and Coggins, M., Evaluating worker vibration exposures using self-reported and direct observation estimates of exposure duration, Applied Ergonomics, 42, 37-45, 2010.

Ministry of Employment and Labor, Industrial Accidents Analysis 2010, 2011.

National Instruments Home Page, Overview of human vibration weighting filters, www.ni.com(retrieved June 10, 2013).

Naver Home Page, 진동, http://terms.naver.com/entry.nhn?cid=661\& docId=521745\&mobile\&categoryId=2602(retrieved June 11, 2013)

Norsonic Home Page, Human vibration, http://www.norsonic.com/ en/applications/vibration/human vibration/(retrieved June 10, 2013).

Radwin, R.G., Armstrong, T.J., Chaffin, D.B., Langolf, G.D. and Albers, J.W., Hand-arm frequency-weighted vibration effects on tactility, International Journal of Industrial Ergonomics, 6, 75-82, 1990.

Rimell, A. and Mansfield, N.J., Design of digital filters for frequency weightings required for risk assessment of workers exposed to vibration. Industrial Health, 45, 512-529, 2007.
Sa, J.S., Understanding of Automotive vibration and noise, Cheongmoongag, 2003.

Smets, M.P.H., Eger, T.R. and Grenier, S.G., Whole-body vibration experienced by haulage truck operators in surface mining operations: A comparison of various analysis methods utilized in the prediction of health risks, Applied Ergonomics, 41, 763-770, 2010.

Tominaga, Y., New frequency weighting of hand-arm vibration, Industrial Health, 43, 509-515, 2005.

\section{Author listings}

Doyung Kee: dhkee@kmu.ac.kr

Highest degree: Ph.D., Department of Industrial Engineering, POSTECH Position title: Professor, Department of Industrial and Management Engineering, Keimyung University

Areas of interest: Population stereotype, product design, posture classification scheme, industrial safety, musculoskeletal disorders

Hee Sok Park: hspark@hongik.ac.kr

Highest degree: $\mathrm{PhD}$, Department of Industrial and Operations Engineering, The University of Michigan

Position title: Professor, Department of Industrial Engineering, Hongik University

Areas of interest: Occupational ergonomics, Musculoskeletal disorders

Date Received : 2013-07-14

Date Revised : 2013-07-26

Date Accepted : 2013-07-26 